\title{
Sensitivity of Nocardia to trimethoprim and sulphonamides in vitro
}

WILLIAM A. BLACK

with the technical assistance of DORA A. McNELLIS

From the University Department of Bacteriology, Glasgow Royal Infirmary

SYNOPSIS Studies in vitro of the sensitivity to trimethoprim and sulphonamides of nine ${ }_{-}^{\circ}$ strains of $N$. asteroides, two strains of $N$. caviae, and one of $N$. blackwellii are presented. $\vec{C}$ No unequivocal evidence of synergism was found. Despite this, the inclusion of trimethoprim₹ in the drug regime when sulphonamides are used in the treatment of nocardiosis is suggested $\vec{\omega}$ on empirical grounds.

In recent years it has been demonstrated that trimethoprim (2,4-diamino-5-(3,4,5-trimethoxybenzyl)-pyrimidine) reacts with sulphonamides in a manner which is strongly synergistic and that drugs, which are themselves bacteriostatic, achieve a bactericidal effect when used together. The pharmacology of this drug combination has been thoroughly evaluated in vitro and in laboratory animals by Bushby and Hitchings (1968). Darrell, Garrod, and Waterworth (1968) confirmed the in-vitro findings of the above authors and reported favourably on the use of a sulphonamide-trimethoprim regime in successfully treating respiratory infections, urinary tract infection, and Gramnegative septicaemia. More recently, there have been further reports of success in the treatment of urinary tract infection (Grüneberg and Kolbe, 1969; Reeves, Faiers, Pursell, and Brumfitt, 1969), of neonatal meningitis due to Escherichia coli (Morzaria, Walton, and Pickering, 1969), and it has been found (Akinkugbe, Lewis, Montefiore, and Okubadejo, 1968) that a combination of sulphamethoxazole and trimethoprim was equal in value to chloramphenicol in the treatment of typhoid fever.

There have, however, been no reports to date on the use of a sulphonamide-trimethoprim mixture in the treatment of Nocardia infections where, despite the advent of many potent new antibiotics, sulphadiazine remains the drug of choice (Strauss, Kligman, and Pillsbury, Received for publication 21 October 1969.
1951; Neu, Silva, Hazen, and Rosenheim, 1967 ;율 Shuster, Klein, Pribor, and Kozub, 1967). Peabody and Seabury (1960), however, in an extensive review of the therapy of actino-0을 mycosis and nocardiosis have suggested that better results might be obtained if sulphadiazine were to be used along with another chemotherapeutic drug in the treatment of the latters condition. Trimethoprim would appear onotheoretical grounds to be the obvious choice of drug for this purpose, and the following paper, 0 in an attempt to substantiate this theory, presents an account of studies in vitro of the effecto of sulphonamide-trimethoprim mixtures on nines strains of Nocardia asteroides, two of $N$. caviae, and one of $N$. blackwellii.

\section{Materials and Methods}

The strain N1 was isolated in this laboratory from a fatal case of nocardiosis, and the strain? NHS was isolated by Dr H. Singh from a fatalo case at another hospital in this area. The origin? of the other species of Nocardia is given in Table I. Staphylococcus aureus (CN 491) and Escherichia coli (CN 314) were included aso controls.

The trimethoprim, sulphamethoxazole, ançी sulphadiazine were freshly prepared before eachs experiment.

Trimethoprim, available as trimethoprim lac 


\begin{tabular}{|c|c|c|}
\hline Strain & Species & Source \\
\hline $\begin{array}{l}\text { N1 } \\
\text { NHS } \\
\text { N8595 }\end{array}$ & $\begin{array}{l}N . \text { asteroides } \\
N . \text { asteroides } \\
N . \text { asteroides }\end{array}$ & $\begin{array}{l}\text { Fatal case of nocardiosis } \\
\text { Fatal case of nocardiosis } \\
\text { National Collection of Type } \\
\text { Cultures }\end{array}$ \\
\hline N6761 & $N$. asteroides & $\begin{array}{l}\text { National Collection of Type } \\
\text { Cultures }\end{array}$ \\
\hline $\begin{array}{l}\text { N770 } \\
\text { CN2470 } \\
\text { RG874 }\end{array}$ & $\begin{array}{l}N . \text { asteroides } \\
N . \text { asteroides } \\
N . \text { asteroides }\end{array}$ & $\begin{array}{l}\text { Mycology Reference Laboratory } \\
\text { Wellcome Bacterial Collection } \\
\text { Institute of Microbiology, } \\
\text { New Jersey }\end{array}$ \\
\hline RG886 & N. asteroides & $\begin{array}{l}\text { Institute of Microbiology, } \\
\text { New Jersey }\end{array}$ \\
\hline $\begin{array}{l}\text { W4 } \\
\text { N1934 }\end{array}$ & $\begin{array}{l}N . \text { asteroides } \\
N . \text { caviae }\end{array}$ & $\begin{array}{l}\text { Westminster Medical School } \\
\text { National Collection of Type } \\
\text { Cultures }\end{array}$ \\
\hline $\begin{array}{l}\text { W2 } \\
\text { N630 }\end{array}$ & $\begin{array}{l}\text { N. caviae } \\
\text { N. blackwellii }\end{array}$ & $\begin{array}{l}\text { Westminster Medical School } \\
\text { National Collection of Type } \\
\text { Cultures }\end{array}$ \\
\hline
\end{tabular}

Table I Origin of Nocardia species

\begin{tabular}{|c|c|c|c|c|c|c|}
\hline \multirow[t]{3}{*}{ Strain } & \multicolumn{4}{|c|}{$\begin{array}{l}\text { Minimum Inhibitory Concentration } \\
\text { Sulphamethoxazole }+ \text { Trimethoprim }\end{array}$} & \multirow[t]{3}{*}{ Trimethoprim } & \multirow[t]{3}{*}{$\begin{array}{l}\text { Sulpha- } \\
\text { methoxazole }\end{array}$} \\
\hline & \multicolumn{4}{|l|}{ Ratio } & & \\
\hline & 20:1 & $10: 1$ & $5: 1$ & $1: 1$ & & \\
\hline N1 & $1 \cdot 25$ & $1 \cdot 25$ & $2 \cdot 5$ & $2 \cdot 5$ & 50 & $1 \cdot 25$ \\
\hline NHS & 1.25 & 1.25 & $1 \cdot 25$ & $2 \cdot 5$ & 50 & 1.25 \\
\hline N8595 & 1.25 & $1 \cdot 25$ & $1 \cdot 25$ & $1 \cdot 25$ & 10 & 5 \\
\hline N6761 & $2 \cdot 5$ & $2 \cdot 5$ & $2 \cdot 5$ & $2 \cdot 5$ & 50 & $2 \cdot 5$ \\
\hline N770 & $2 \cdot 5$ & $2 \cdot 5$ & $2 \cdot 5$ & $2 \cdot 5$ & 50 & $2 \cdot 5$ \\
\hline CN2470 & $2 \cdot 5$ & $1 \cdot 25$ & $1 \cdot 25$ & $1 \cdot 25$ & 50 & $2 \cdot 5$ \\
\hline RG874 & 1.25 & $1 \cdot 25$ & 1.25 & 0.625 & 25 & 0.625 \\
\hline RG886 & 2.5 & 2.5 & 2.5 & $2 \cdot 5$ & 50 & 2.5 \\
\hline W4 & $2 \cdot 5$ & $1 \cdot 25$ & $1 \cdot 25$ & $1 \cdot 25$ & 25 & $1 \cdot 25$ \\
\hline N1934 & $2 \cdot 5$ & $1 \cdot 25$ & 1.25 & $1 \cdot 25$ & 50 & $2 \cdot 5$ \\
\hline W2 & $2 \cdot 5$ & $2 \cdot 5$ & $2 \cdot 5$ & 2.5 & 50 & 2.5 \\
\hline N630 & $1 \cdot 25$ & $1 \cdot 25$ & $1 \cdot 25$ & $1 \cdot 25$ & 25 & $1 \cdot 25$ \\
\hline \multirow{3}{*}{$\begin{array}{l}\text { Staph. aureus } \\
\text { CN491 } \\
\text { Esch. coli } \\
\text { CN314 }\end{array}$} & & & & & & \\
\hline & 0.625 & $<0.312$ & $<0.312$ & $<0.312$ & $<0.312$ & 5 \\
\hline & 0.625 & 0.625 & $<0.312$ & $<0.312$ & $<0.312$ & 10 \\
\hline
\end{tabular}

Table II Minimum inhibitory concentrations of sulphamethoxazole, trimethoprim, and various combinations

\begin{tabular}{llll}
\hline$S: T$ & $M I C(\mu \mathrm{g} / \mathrm{ml})$ & & \\
\cline { 2 - 4 } Ratio & $2 \cdot 5$ & $1 \cdot 25$ & $0 \cdot 625$ \\
& $S: T$ & $S: T$ & $S: T$ \\
\hline $20: 1$ & $2 \cdot 38: 0 \cdot 12$ & $1 \cdot 19: 0 \cdot 06$ & $0 \cdot 595: 0 \cdot 03$ \\
$10: 1$ & $2 \cdot 27: 0 \cdot 23$ & $1 \cdot 14: 0 \cdot 11$ & $0 \cdot 568: 0 \cdot 051$ \\
$5: 1$ & $2 \cdot 09: 0 \cdot 41$ & $1 \cdot 04: 0 \cdot 21$ & $0 \cdot 521: 0 \cdot 104$ \\
$1: 1$ & $1 \cdot 25: 1 \cdot 25$ & $0 \cdot 625: 0 \cdot 625$ & $0 \cdot 312: 0 \cdot 312$ \\
\hline
\end{tabular}

Table III Amounts of sulphamethoxazole $(S)$ and trimethoprim $(T)$ in the combined MIC at the various ratios

tate, was freely soluble in water. The sulphonamides were first dissolved in water at an alkaline $p \mathrm{H}$ by the addition of $\mathrm{N} / 1 \mathrm{NaOH}$ after which it was found possible to readjust the $p \mathrm{H}$ to 7.5 with $\mathrm{N} / 1 \mathrm{HCl}$ without precipitation occurring. From basic dilutions in nutrient broth (OxoidCM1) containing $10,000 \mu \mathrm{g} / \mathrm{ml}$, tube dilutions containing 2,000-500 $\mu \mathrm{g} / \mathrm{ml}$ and $200-6 \cdot 25 \mu \mathrm{g} / \mathrm{mlc}$ were prepared for each drug. Aliquots of the $\cong$ $2,000 \mu \mathrm{g} / \mathrm{ml}$ solutions of the three drugs were then taken and both the sulphamethoxazole and the sulphadiazine mixed with trimethoprim to give sulphonamide:trimethoprim ratios of $20: 1,10: 1,5: 1$, and $1: 1$, and, from each of these $2,000 \mu \mathrm{g} / \mathrm{ml}$ mixtures, dilutions ranging from 2,000 to $6.25 \mu \mathrm{g} / \mathrm{ml}$ were made as before. 흐

Universals containing measured $18 \mathrm{ml}$ aliquots $\frac{\overline{\bar{p}}}{\bar{p}}$ of molten diagnostic sensitivity test agar (Oxoid- $ه$ CM261) were allowed to cool to about $50^{\circ} \mathrm{C}$ to $60^{\circ} \mathrm{C}$ and, before pouring, $1 \mathrm{ml}$ of lysed horse ${ }^{\infty}$ blood and $1 \mathrm{ml}$ of one of the antibiotic dilutions. were added to each giving a final antibiotic $\overrightarrow{\vec{E}}$ concentration ranging from 100 to $0.312 \mu \mathrm{g} / \mathrm{ml}$.

A measured loopful $(0.0025 \mathrm{ml})$ of a six-houro mechanically agitated culture in nutrient brothis of each Nocardia strain was then inoculated $\mathcal{G}$ on to every plate and the inoculum spread over. an area of about $1 \mathrm{sq} \mathrm{cm}$. Tween 80 was added N to the broth in later experiments to reduces granularity of the broth culture and make iteasier to standardize the dose of organisms, $\subseteq$ which were usually present in a concentration of $10^{5}$ to $10^{6} / \mathrm{ml}$. This procedure did not affect $\vec{\bullet}$ the interpretation of the results. Using the above dose, a heavy but not confluent growth was obtained and the minimum inhibitory concentra-o tion (MIC) was interpreted as in previous studies, namely, the lowest concentration of antimicrobialo that inhibited at least $90 \%$ of the control growth (Bushby and Hitchings, 1968).

\section{Results}

The results, which were read after 48 hours incubation at $37^{\circ} \mathrm{C}$, are detailed in Tables $\mathrm{IP}$. and III.

From these it can be seen that the sulphona mide MICs are satisfactory and could be quite easily achieved in vivo by standard dosages $>$ Raich, Casey, and Hall (1961), for example를. showed that a blood sulphonamide level of $140 \mu \mathrm{g} / \mathrm{ml}$ could be maintained by a dosage of 6 to $8 \mathrm{~g}$ of sulphadiazine per day, and Garrod and O'Grady (1968) report a peak plasma level of $100 \mu \mathrm{g} / \mathrm{ml}$ after an initial dose of $4 \mathrm{~g}$ of sulphadiazine followed by $1 \mathrm{~g}$ fouco hourly. Stokes (1968) maintains that for mosw acute infections the average blood antibiotice level should exceed the MIC by a safety factoro of 2 or 4, but for actinomycosis (and presumably? nocardiosis) the safety factor should be higher尺 These criteria are satisfied by the present figures which show an average MIC of about $2.5 \mu \mathrm{g} / \mathrm{mb}$ with a potential blood level of 100 to $140 \mu \mathrm{g} / \mathrm{ml}$ ie, 20 to 30 times the MIC.

The sensitivity to trimethoprim is disappoint ing. In other series the average MIC for mose of the bacteria tested was of the order of $1 \mu \mathrm{g} / \mathrm{ml}$ 
or less (Bushby and Hitchings, 1968; Darrell et al, 1968) whereas with the Nocardia in our series the MIC of trimethoprim was $50 \mu \mathrm{g} / \mathrm{ml}$ in eight out of the 12 strains tested, $25 \mu \mathrm{g} / \mathrm{ml}$ in three strains, and $10 \mu \mathrm{g} / \mathrm{ml}$ in the remaining strain. As Bushby and Hitchings (1968) were able to obtain peak serum levels of only 2 to 3 $\mu \mathrm{g} / \mathrm{ml}$ of trimethoprim one hour after giving an oral dose of $250 \mathrm{mg}$, it must be concluded that the use of trimethoprim alone would be of no value in the treatment of nocardiosis.

In the case of Neisseria gonorrhoeae, it has been shown (Bushby and Hitchings, 1968) that there was a high degree of potentiation of sulphadiazine by trimethoprim despite the fact that these organisms are relatively resistant to the latter drug. The results shown in Tables II and III, however, indicate that this synergistic effect was not demonstrated unequivocally in any of the four sulphonamide:trimethoprim ratios tested. There did, however, seem to be some enhancement of the sulphonamide when this was used with an equal amount of trimethoprim but in only one or two cases was there more than a two-fold difference between the sulphonamide acting alone and the sulphonamide combined with trimethoprim.

Sulphamethoxazole is the sulphonamide of choice for use with trimethoprim as these drugs are absorbed and excreted at the same rate. We chose to test sulphadiazine as well as sulphamethoxazole because the former has been used most widely in the treatment of nocardiosis (Peabody and Seabury, 1960). Tested individually, the MIC of sulphadiazine is the same, or twofold higher, than that of sulphamethoxazole, a finding which tallies with that of Neipp (1964) in his survey of comparative activities of sulphonamides in vitro. Sulphadiazine displayed the same lack of marked synergistic activity with trimethoprim as did sulphamethoxazole.

\section{Discussion}

At the time of publication, sulphadiazine remains the drug of choice in the treatment of nocardiosis (Strauss et al, 1951; Neu et al, 1967; Shuster et al, 1967). There has, however, been a recent report of the successful treatment of a case of cerebral nocardiosis using a combination of sulphonamides and cycloserine (Hoeprich, Brandt, and Parker, 1968), and Vasarinsh (1968) reported the successful treatment of a case of primary cutaneous nocardiosis using a combination of sulphadiazine, erythromycin, and sulfone. The fact that no unequivocal synergism with trimethoprim was seen in vitro was disappointing but might have been expected from the relatively high MIC of the latter for, in their study of urinary tract infection, Reeves et al (1969) showed that the failure of treatment in all species tested was associated with a rela-c tively high resistance to trimethoprim.

On the other hand, Wright and Grimble (1969) found that the cure rate in gonorrhoea was only $30 \%$ when treated with sulphamethoxa-ô zole but that when this was combined with trimethoprim the cure rate rose to $80 \%$ even although the MIC of trimethoprim for theo gonococcus has been shown to be as high inㅡㅡ some cases as that which we found for Nocardia $\overline{\bar{p}}$ (Bushby and Hitchings, 1968). Again, Csonka and $\mathbb{\Omega}$ Knight (1967) have shown that gonorrhoea cang be successfully treated with a sulphonamide- trimethoprim mixture even although trimetho-. prim itself is useless in treating this condition. $\vec{\omega}$ It must be remembered, however, that a syn- $\omega$ ergistic effect of sulphonamide and trimethoprimo on the gonococcus has been demonstratedit in vitro (Bushby and Hitchings, 1968) whereas ${ }^{\omega}$ we have failed to demonstrate this convincingly: with Nocardia.

The question of therapy is not merely ofo academic interest as nocardiosis is a chronic, disabling condition which even if correctlyc diagnosed and treated is still attended by a highर morbidity and mortality. Hoeprich et al (1968) $\vec{\bullet}$ in a review of 148 cases of nocardiosis report $ठ$ a fatality rate of about $87 \%$ in patients with cerebral involvement and $10 \%$ in patients witho uncomplicated pulmonary disease who had received sulphonamide therapy. In dealing with a condition of this severity, the present findings cannot justify any reduction in what is accepted $\stackrel{\varrho}{\rightarrow}$ as a reasonable dose of sulphonamide, viz, $\overrightarrow{0}$ 6-8 $\mathrm{g} /$ day, although the addition to this regimen of $1 \mathrm{~g} /$ day of trimethoprim (which is the maximum clinically acceptable dose) would appear. worthy of trial, as our laboratory findings suggesto that a 1:1 sulphonamide:trimethoprim ratio(and, to a lesser extent a 5:1 ratio) does give some minor degree of synergism. The choice of sul-ô phonamide used in treating nocardiosis will depend on whether or not trimethoprim is too be added to the regime. If it is, then sulpha methoxazole would be preferable; if it is not? then sulphadiazine should be chosen because of its proven efficacy.

It is hoped that this report will stimulate further investigation of this topic in an effort to reduce the morbidity and mortality of no-o cardiosis to a more acceptable level.

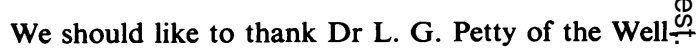
come Foundation for supplying trimethoprim lactate, $\square$ sulphamethoxazole, and the control strains of

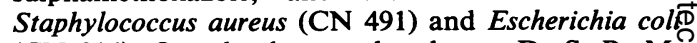
(CN 314). Our thanks are also due to Dr S. R. M $\frac{\text { }}{\mathbb{D}}$ Bushby of the Wellcome Research Laboratories for helpful criticism and advice. May \& Baker kindly? supplied the sulphadiazine. Our grateful thanks are? also due to the following who provided us witho strains of Nocardia: Dr Ruth E. Gordon of the Institute of Microbiology, New Jersey; Professof B. W. Lacey of Westminster Medical School; Dr I? 
Murray of the Mycological Reference Laboratory, London; Miss E. Jean Shelton of the National Collection of Type Cultures and the curator of the Wellcome Bacterial Collection.

\section{References}

Akinkugbe, D. O., Lewis, E. A., Montefiore, D., and Okubadejo O. A. (1968). Trimethoprim and sulphamethoxazole in typhoid. Brit. med.J., 3, 721-722.

Bushby, S. R. M., and Hitchings, G. H. (1968). Trimethoprim, a sulphonamide potentiator. Brit. J. Pharmacol., 33, 72-90.

Csonka, G. W., and Knight, G. J. (1967). Therapeutic trial of trimethoprim as a potentiator of sulphonamides in gonorrhoea. Brit. J. vener. Dis., 43, 161-165.

Darrell, J. H., Garrod, L. P., and Waterworth, P. M. (1968). Trimethoprim: laboratory and clinical studies. J. clin. Path., 21, 202-209.

Garrod, L. P., and O'Grady, F. (1968). Antibiotic and Chemotherapy, 2nd ed., p. 26. Livingstone, Edinburgh.

Grüneberg, R. N., and Kolbe, R. (1969). Trimethoprim in the treatment of urinary infections in hospital. Brit. med.J., 1 , 545-547.

Hoeprich, P. D., Brandt, D., and Parker, R. H. (1968). Nocardial brain abscess cured with cycloserine and sulfonamides. Amer.J. med. Sci., 255, 208-216.

Morzaria, R. N., Walton, I. G., and Pickering, D. (1969).Neonatal meningitis treated with trimethoprim and sulphamethoxazole. Brit. med. J., 2, 511-512.

Neipp, L. (1964). Antibacterial chemotherapy with sulfonamides In Experimental Chemotherapy, vol. 2, edited by R. J. Schnitzer and F. Hawking, p. 169. Academic Press, New York and London.
Neu, H. C., Silva, M., Hazen, E., and Rosenheim, S. H. (1967).C Necrotizing nocardial pneumonitis. Ann. intern. Med., 66, $\Omega$ 274-284.

Peabody, J. W., Jr., and Seabury, J. H. (1960). Actinomycosis and nocardiosis. Amer.J. Med., 28, 99-115.

Raich, R. A., Casey, F., and Hall, W. H. (1961). Pulmonary and $\stackrel{\mathscr{P}}{+}$ cutaneous nocardiosis. Amer. Rev. resp. Dis., 83, 505-509.

Reeves, D. S., Faiers, M. C., Pursell, R. E., and Brumfitt, W. (1969). Trimethoprim-sulphamethoxazole: comparative study in urinary infection in hospital. Brit. med. J., 1, S 541-544.

Shuster, M., Klein, M. M., Pribor, H. C., and Kozub, W. (1967). Brain abscess due to nocardia. Arch. intern. Med., 120, 응 610-614.

Stokes, E. J. (1968). Clinical Bacteriology, 3rd ed., p. 176. Arnold, London.

Strauss, R. E., Kligman, A. M., and Pillsbury, D. M. (1951). ע The chemotherapy of actinomycosis and nocardiosis. Amer. Rev. Tuberc., 63, 441-448.

Vasarinsh, P. (1968). Primary cutaneous nocardiosis. Arch. Derm., 98, 489-493.

Wright, D. J. M., and Grimble, A. (1969). Trimethoprim mixture $\vec{\omega}$ Brit. med.J., 1, 637.

\section{Addendum}

Since the completion of this work it has beenc observed that our original strain $\mathrm{N} 1$ is sensitive응 in vitro to $0.625 \mu \mathrm{g} / \mathrm{ml}$ of fucidin. At present weare in the process of investigating the comparative $\subseteq$ MICs of fucidin and sulphonamides for Nocardia. 